\title{
PENGEMBANGAN MEDIA PEMBELAJARAN MODUL DASAR-DASAR KONSTRUKSI BANGUNAN DAN TEKNIK PENGUKURAN TANAH BERBASIS E-PUBLICATION UNTUK SMK BERDASARKAN GAYA BELAJAR SISWA
}

Fitri Dwi Astutik ${ }^{1}$, Rima Sri Agustin ${ }^{2}$, Sukatiman $^{2}$

Email: fitriadwi473@gmail.com

\begin{abstract}
ABSTRAK
Penelitian ini bertujuan untuk mengetahui (1) proses pengembangan media pembelajaran modul Dasar-Dasar Konstruksi Bangunan dan Teknik Pengukuran Tanah berbasis e-publication untuk SMK berdasarkan gaya belajar siswa dan (2) tingkat kelayakan pengembangan media pembelajaran modul Dasar-Dasar Konstruksi Bangunan dan Teknik Pengukuran Tanah berbasis e-publication untuk SMK berdasarkan gaya belajar siswa. Penelitian ini merupakan Penelitian Pengembangan (Research and Development) yang dilaksanakan dengan menggunakan model pengembangan media pembelajaran MDLC (Multimedia Development Life Cycle). Subyek penelitian ini adalah siswa kelas X BKP SMKN 2 Surakarta pada mata pelajaran Dasar-Dasar Konstruksi Bangunan dan Teknik Pengukuran Tanah. Data diperoleh dari observasi, dokumentasi dan kuesioner. Teknik analisis data menggunakan deskriptif kualitatif. Hasil penelitian menunjukkan bahwa sebagian besar siswa calon pengguna media pembelajaran memiliha gaya belajar read sehingga modul yang dikembangkan berupa teks. Hasil validasi ahli materi dan media diperoleh rata-rata prosentase sebesar 80,12\% dan termasuk dalam kategori sangat baik. Respon dari guru pengampu mata pelajaran dan siswa diperoleh ratarata prosentase sebesar $91,30 \%$ dan merupakan dalam kategori sangat baik. Dengan demikian media pembelajaran berbasis $e$-publication yang telah dikembangkan dinyatakan layak untuk digunakan.
\end{abstract}

Kata Kunci: Pengembangan, media pembelajaran, e-publication, $M D L C$

\footnotetext{
${ }^{1}$ Mahasiswa Program Studi Pendidikan Teknik Bangunan FKIP UNS

${ }^{2}$ Dosen Pengajar Program Studi Pendidikan Teknik Bangunan FKIP UNS
} 


\title{
DEVELOPMENT OF A BASIC LEARNING MODULS FOR BUILDING CONSTRUCTION AND SOIL MEASUREMENT BASED OF E-PUBLICATION \\ TECHNIQUES FOR VOCATIONAL SCHOOL BASED ON STUDENT \\ LEARNING STYLES
}

Fitri Dwi Astutik ${ }^{1}$, Rima Sri Agustin ${ }^{2}$, Sukatiman $^{2}$

Email: fitriadwi473@gmail.com

\begin{abstract}
This research aims to determine (1) The process of media development learning modules of Building Construction Basics and Soil Measurement Techniques based on epublication for Vocational based on student learning styles and (2) Level of feasibility of media development learning modules of Building Construction Basics and Soil Measurement Techniques based on e-publication for SMK based on student learning styles. This kind of investigation is Research and Development that implemented using the MDLC (Multimedia Development Life Cycle) learning media development model. The subject of this research were students of class X BKP SMKN 2 Surakarta in the subjects of Building Construction Basics and Soil Measurement Techniques. Data obtained from observation, documentation and questionnaire. Data analysis techniques used qualitative descriptive. The result of this research showed that most of the prospective students of learning media users choosed learning styles to read so that the modules developed were in the form text. The result of the experts material and media validation obtained an average of $80.12 \%$ and included in the excellent category. The response of subject teachers and students were obtained by an average percentage of $91.30 \%$ and was in very good category. Thus e-publication based learning media that have been developed were declared feasible to use.
\end{abstract}

Keywords: Development, learning media, e-publication, $M D L C$

\footnotetext{
${ }^{1}$ Student of Building Engineering Education FKIP UNS

${ }^{2}$ Lecturer of Building Engineering Education FKIP UNS
} 


\section{PENDAHULUAN}

$\begin{array}{ccc}\begin{array}{c}\text { Proses } \\ \text { merupakan }\end{array} & \begin{array}{c}\text { belajar } \\ \text { proses }\end{array} & \begin{array}{r}\text { mengajar } \\ \text { komunikasi, }\end{array}\end{array}$
penyampaian pesan dari pengantar ke penerima. Media pembelajaran memiliki peran sebagai perantara pesan tersebut. Criticos dalam Daryanto (2013: 4) mengemukakan media merupakan salah satu komponen komunikasi, yaitu sebagai pembawa pesan dari komunikator menuju komunikan. Menurut Fiedler (1997: 219), media pembelajaran akan berkembang seiring dengan perkembangan teknologi dan komunikasi di era digital. "Age of digital communication" adalah istilah oleh Roger Fiedler sebagai tanda datangnya era digital seiring berkembangnya E-Book. E-book atau buku digital merupakan salah satu bentuk media pembelajaran.

Siswa akan lebih aktif belajar jika diberikan visualisasi tentang materi pelajaran dengan buku digital. Siswa cenderung kesulitan memahami materi karena materi tersebut masih abstrak dan di luar pengalaman siswa sehingga diperlukan visualisasi dengan buku digital untuk menjelaskannya. Salah satu jenis buku digital yang telah dikembangkan adalah buku digital dengan format E-pub (Electronik publication). E-pub menggantikan peran Open e-Book sebagai format buku terbuka (Southeast Asian Ministers of Educatioan Organization Regional Open Learning Centre (SEAMOLEC),2014: 5).

Buku digital dengan format $E-p u b$ (Electronik publication) masih belum banyak digunakan pada kegiatan pembelajaran. Salah satunya pada mata pelajaran Dasar-Dasar Konstruksi Bangunan dan Teknik Pengukuran Tanah di SMK Negeri 2 Surakarta. Masalah yang terjadi adalah guru menjelaskan dan menuliskan materi di papan tulis kemudian siswa mencatat. Berkaitan dengan hal ini, pengembangan media pembelajaran berupa modul DasarDasar Konstruksi Bangunan dan Teknik Pengukuran Tanah untuk pegangan siswa sangat diperlukan untuk menjadi alternatif dalam mengatasi permasalahan proses belajar mengajar tersebut.

Selain itu, dalam proses belajar mengajar yang diterapkan di sekolah belum sesuai dengan karakteristik dan gaya belajar siswa, yang mana gaya belajar tersebut meliputi empat karakteristik yakni visual, auditorial, read, dan kinesthetic. Media pembelajaran modul berbasis e-publication diharapkan dapat menjadikan waktu belajar lebih efektif. Siswa dapat mempelajari materi pelajaran secara mandiri dimanapun dan kapanpun mereka berada melalui smartphone yang mereka miliki sesuai dengan karakteristik dan gaya belajar siswa. Siswa juga tidak perlu mencatat semua materi pelajaran waktu belajar mengajar menjadi lebih produktif.

Penggunaan modul dalam pembelajaran bertujuan agar siswa dapat belajar mandiri tanpa atau dengan minimal dari guru sesuai dengan pendapat Schramm yang menyatakan bahwa modul merupakan satu satu media untuk belajar secara individu. Sedangkan Cara belajar yang dimiliki siswa sering disebut dengan gaya belajar atau modalitas belajar siswa. Gaya belajar sangat penting dalam memberi alternatif kepada siswa untuk memilih pembelajaran khas mereka sendiri sehingga dapat menciptakan lingkungan belajar yang menarik bagi siswa (Othman, Norasmah, 2010). Terdapat berbagai jenis gaya belajar yang dikemukakan oleh para ahli pendidikan. Salah satunya yang banyak dan mudah digunakan adalah gaya belajar VARK (Visual Auditorik Read Kinesthetic) yang 
dicetuskan oleh Fleming dan Bonwell (2001).

Penggunaan media pembelajaran yang tepat bertujuan mempermudah siswa dalam menyerap informasi yang diberikan oleh guru dan membuat waktu proses belajar mengajar menjadi lebih efektif. belajar mengajar menjadi lebih efektif. Oleh karena itu, media pembelajaran memiliki peran yang penting untuk menciptakan pembelajaran yang efektif dan efisien. Pembuatan media pembelajaran juga harus disesuaikan dengan gaya belajar siswa agar dapat mempermudah siswa dalam memahami pelajaran melalui media tersebut. Gaya belajar tersebut meliputi gaya belajar visual, audio, reading/writing, atau kinesthetic.

Penelitian ini menggunakan salah satu dari beberapa model pengembangan media pembelajaran di atas yakni pengembangan media pembelajaran model Multimedia Development Life Cycle (MDLC). Model ini dipilih karena memiliki tahapan-tahapan yang rinci untuk pengembangan sebuah media pembelajaran. Selain itu, hasil penelitian Indrawaty, Rosmala, dan Ramdhanial (2013: 10) menunjukkan bahwa pengembangan media pembelajaran menggunakan model $M D L C$ dapat menghasilkan media pembelajaran yang baik untuk dapat digunakan sebagai pembelajaran.

Media pembelajaran yang telah dikembangkan belum bisa langsung diterapkan pada pembelajaran tetapi perlu dilakukan evaluasi terlebih dahulu terhadap hasil pengembangan media pembelajaran berbasis e-publication ini. Hasil evaluasi yang diperolah dijadikan pertimbangan apakah media pembelajaran ini sudah memenuhi kriteria media pembelajaran yang baik sehingga layak untuk diterapkan dalam proses belajar mengajar.

\section{METODE PENELITIAN}

Penelitian ini merupakan penelitian pengembangan yang bertujuan untuk mengembangkan suatu media pembelajaran. Media pembelajaran yang dikembangkan adalah media pembelajaran dasar-dasar konstruksi bangunan dan teknik pengukuran tanah yang berbasis pada buku digital yakni Elektronik Publication (E-pub). Aplikasi yang digunakan adalah aplikasi Sigil sebagai aplikasi utama dan aplikasi lain sebagai aplikasi pendukung. Referensi yang digunakan untuk pembuatan media pembelajaran adalah bahan ajar buku konstruksi bangunan dan teknik pengukuran tanah untuk SMK.

Jenis pendekatan penelitian ini menggunakan pendekatan pengembangan prosedural yang bersifat deskriptif kualitatif, menunjukkan langkah-langkah yang harus diikuti untuk menghasilkan suatu media pembelajaran. Untuk menghasilkan suatu media pembelajaran yang baik diperlukan sebuah perencanaan kerja atau prosedur kerja yang sistematis agar pengembangan media pembelajaran dapat berjalan dengan baik.

Model ini digunakan karena media pembelajaran dasar-dasar konstruksi bangunan yang dikembangkan terdiri dari komponen teks, gambar, audio, serta video yang merupakan beberapa komponen media pembelajaran. Oleh karena itu, model MDLC dipandang lebih relevan digunakan dalam pengembangan media pembelajaran dasar-dasar konstruksi bangunan ini.

Pada penelitian ini instrumen penelitian yang digunakan adalah kuesioner. Kuesioner yang digunakan pada penelitan ini ada 4 jenis yaitu kuesioner untuk ahli media, ahli materi, guru pengampu mata pelajaran dasardasar konstruksi bangunan dan teknik pengukuran tanah serta 10 siswa kelas BKP (Bisnis Konstruksi dan Properti). 
Teknik analisis data menggunakan analisis deskripstif kualitatif untuk dapat mendeskripsikan dengan jelas data yang diperoleh dari responden melalui hasil pengisian angket. Menurut Arthana dan Dewi (2005: 80) teknik analisis data dapat menggunakan teknik perhitungan PSA (Prosentase Setiap Aspek).

Rumus yang digunakan adalah sebagai berikut :

$$
P S A=\frac{\sum x}{\sum y} X 100 \%
$$

Dimana :

$\mathrm{x}=$ Alternatif jawaban terpilih setiap aspek

$\mathrm{y}=$ Alternatif jawaban ideal setiap aspek

Arikunto Arthana dan Dewi (2005: 80) menjelaskan bahwa hasil presentase tersebut kemudian dimaknai dalam kriteria penilaian yang dapat dijelaskan pada tabel sebagai berikut :

Tabel 1. Kriteria Penilaian

\begin{tabular}{cc}
\hline Presentase & Kriteria \\
\hline $100-80$ & Sangat Baik \\
\hline $79-65$ & Baik \\
\hline $64-40$ & Cukup \\
\hline $39-0$ & Kurang \\
\hline
\end{tabular}

\section{HASIL PENELITIAN}

\section{a. Proses Pengembangan Media Pembelajaran}

Pengembangan media pembelajaran modul Dasar-Dasar Konstruksi Bangunan dan Teknik Pengukuran Tanah berbasis E-publication ini menggunakan model pengembangan MDLC (Multimedia Development Life Cycyle) yang memiliki 6 tahap. Tahaptahap tersebut antara lain : Konsep (Concept), Desain (Design), Pengumpulan Material (Obtaining Content Material), Penyusunan (Assembly), Pengujian (Testing), dan Distribusi (Distribution).

Tahap pertama adalah analisis gaya belajar siswa. Hasil gaya belajar siswa dapat dilihat sebagai berikut :

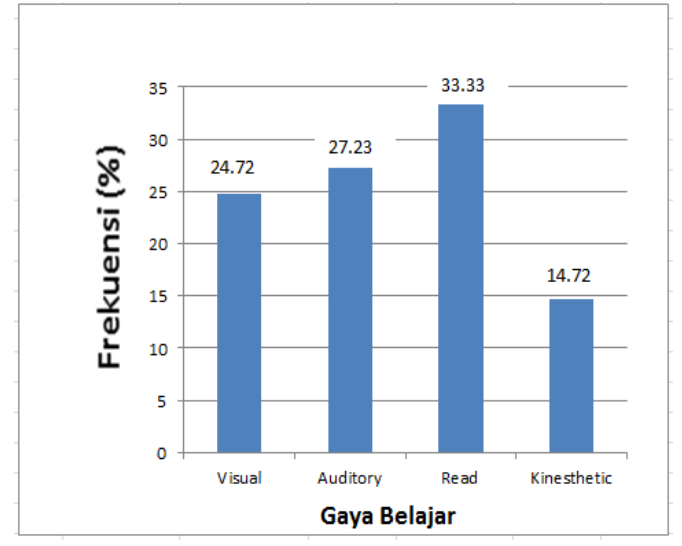

Gambar 1. Hasil analisis gaya belajar

Berdasarkan gambar 1 dapat dilihat bahwa mayoritas gaya belajar siswa BKP tahun akademik 2018/2019 adalah read ditunjukkan dengan prosentase sebesar 33,33\% yang merupakan prosentase tertinggi. Hasil analisis gaya belajar tersebut akan dijadikan dasar pengembangan media pembelajaran.

Tahap kedua adalah membuat kerangka modul. Kerangka tersebut memiliki 3 bagian utama yakni pendahuluan, inti, dan penutup.

Tahap ketiga adalah pengumpulan materi. Berdasarkan hasil analisis materi telah diketahui kompetensi dasar yang akan dimasukkan ke dalam modul yakni kompetensi dasar menerapkan dan mengelola spesifikasi kayu dan beton . Referensi yang digunakan diambil dari buku pegangan yang digunakan oleh guru pengampu mata pelajaran Dasar-Dasar Konstruksi Bangunan dan Teknik Pengukuran Tanah (Robert Siagian, 2014), Buku Ajar Konstruksi Beton I (I Putu Laintarawan, dkk. 2009), dan Ilmu Konstruksi Bangunan Kayu (Ir. Heinz Frick, 1999). Selain itu, referensi juga menggunakan dari sumber-sumber lain untuk melengkapi materi modul.

Pengembangan media pembelajaran modul Dasar-Dasar Konstruksi Bangunan dan Teknik Pengukuran Tanah berbasis $e$ - 
publication membutuhkan beberapa software. Beberapa software yang digunakan antara lain : Sigil, Microsoft word, Corel Draw, dan Gitden Reader.

Tahap keempat adalah tahap pengujian. Pengujian terdiri dari 2 yakni pengujiian sistem dan pengujian ahli. Berikut ini merupakan tabel pengujian sistem dan pengujian ahli : Tabel 2. Hasil pengujian sistem

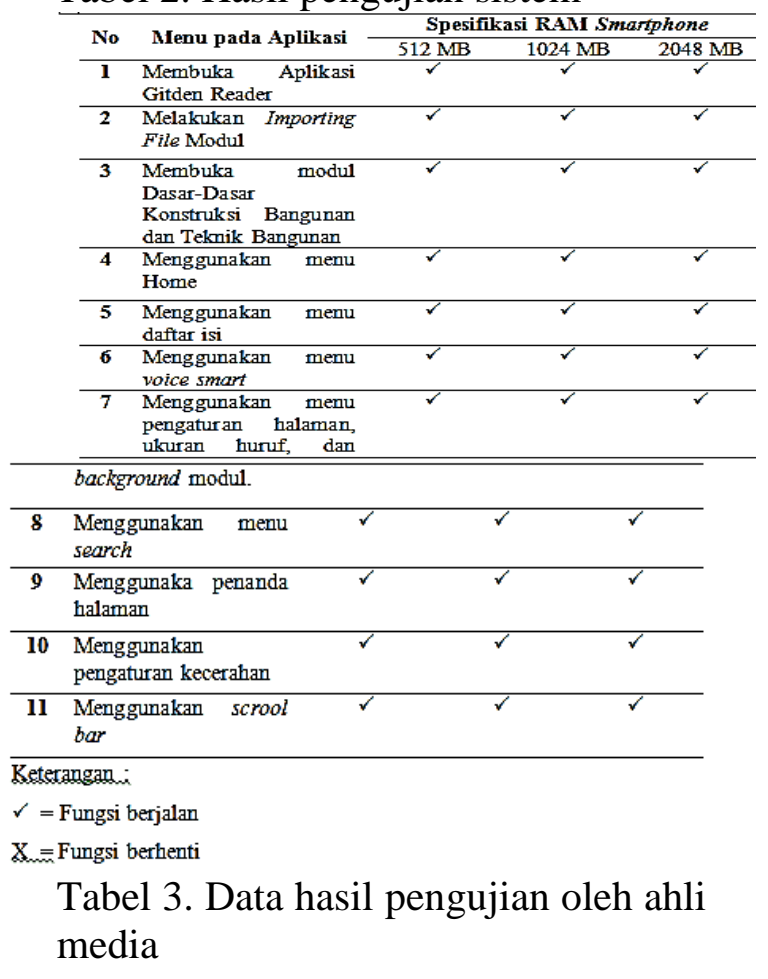

\begin{tabular}{ccccl}
\hline No. & $\begin{array}{c}\text { No. } \\
\text { Butir }\end{array}$ & $\begin{array}{c}\text { Total } \\
\text { Skor }\end{array}$ & $\begin{array}{c}\text { Skor } \\
\text { Maksimal }\end{array}$ & $\begin{array}{c}\text { Indikator } \\
\text { Penilaian }\end{array}$ \\
\hline $\mathbf{1}$ & 1 & 4 & 4 & Desain Sampul \\
$\mathbf{2}$ & 2 & 4 & 4 & Desain Sampul \\
$\mathbf{3}$ & 3 & 4 & 4 & Desain Sampul \\
$\mathbf{4}$ & 4 & 4 & 4 & Desain Sampul \\
$\mathbf{5}$ & 5 & 3 & 4 & Desain Sampul \\
$\mathbf{6}$ & 6 & 3 & 4 & Desain Sampul \\
$\mathbf{7}$ & 7 & 3 & 4 & Desain Isi \\
$\mathbf{8}$ & 8 & 3 & 4 & Desain Isi \\
$\mathbf{9}$ & 9 & 3 & 4 & Desain Isi \\
$\mathbf{1 0}$ & 10 & 4 & 4 & Desain Isi \\
$\mathbf{1 1}$ & 11 & 3 & 4 & Desain Isi \\
$\mathbf{1 2}$ & 12 & 3 & 4 & Desain Isi \\
$\mathbf{1 3}$ & 13 & 4 & 4 & Desain Isi \\
$\mathbf{1 4}$ & 14 & 4 & 4 & Desain Isi \\
$\mathbf{1 5}$ & 15 & 3 & 4 & Desain Isi \\
$\mathbf{1 6}$ & 16 & 3 & 4 & Desain Isi \\
$\mathbf{1 7}$ & 17 & 3 & 4 & Desain Isi \\
$\mathbf{1 8}$ & 18 & 3 & 4 & Desain Isi \\
$\mathbf{1 9}$ & 19 & 3 & 4 & Desain Isi \\
$\mathbf{2 0}$ & 20 & 3 & 4 & Desain Isi \\
$\mathbf{2 1}$ & 21 & 3 & 4 & Desain Isi \\
$\mathbf{2 2}$ & 22 & 3 & 4 & Desain Isi \\
$\mathbf{2 3}$ & 23 & 3 & 4 & Desain Isi \\
\hline $\mathbf{T O T A L}$ & $\mathbf{7 6}$ & $\mathbf{9 2}$ & \\
\hline & & & & \\
\hline
\end{tabular}

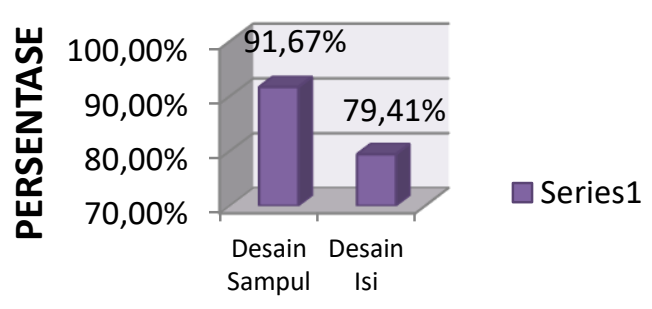

INDIKATOR PENILAIAN

Gambar 2. Hasil Penilaian Validasi ahli Media 
Tabel 4. Data hasil pengujian oleh ahli materi

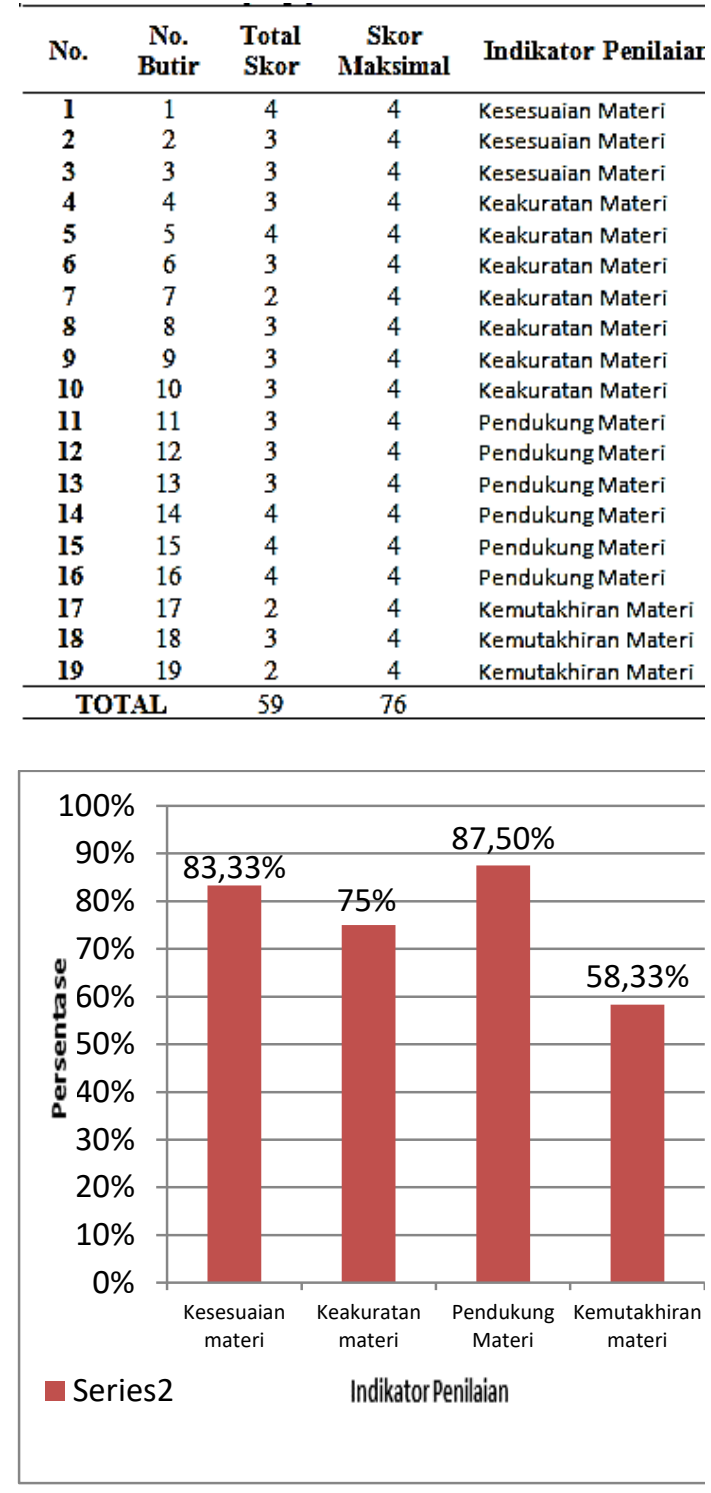

Gambar 3. Hasil Penilaian Validasi ahli Materi

\section{b. Tingkat kelayakan Media Pembelajaran}

Tahap ini merupakan tahap evaluasi yang dilakukan oleh pendidik (guru) untuk memperoleh respon terhadap media pembelajaran yang telah dikembangkan. Tahap evaluasi dilakukan dengan membagikan kuesioner kepada guru pengampu mata pelajaran Dasar-Dasar
Konstruksi Bangunan dan Teknik Pengukuran Tanah serta 10 siswa kelas X BKP (Bisnis Konstruksi dan Properti) SMKN 2 Surakarta.

Hasil respon guru pengampu dapat dijelaskan dengan tabel sebagai berikut : Tabel 5 Data hasil evaluasi oleh guru pengampu

\begin{tabular}{llll}
\hline No. & $\begin{array}{l}\text { No. } \\
\text { Butir }\end{array}$ & $\begin{array}{l}\text { Total } \\
\text { Skor }\end{array}$ & $\begin{array}{l}\text { Skor } \\
\text { Maksimal }\end{array}$ \\
\hline $\mathbf{1}$ & 1 & 4 & 4 \\
$\mathbf{2}$ & 2 & 4 & 4 \\
$\mathbf{3}$ & 3 & 3 & 4 \\
$\mathbf{4}$ & 4 & 4 & 4 \\
$\mathbf{5}$ & 5 & 4 & 4 \\
$\mathbf{6}$ & 6 & 4 & 4 \\
$\mathbf{7}$ & 7 & 4 & 4 \\
$\mathbf{8}$ & 8 & 4 & 4 \\
$\mathbf{9}$ & 9 & 4 & 4 \\
$\mathbf{1 0}$ & 10 & 4 & 4 \\
$\mathbf{1 1}$ & 11 & 4 & 4 \\
$\mathbf{1 2}$ & 12 & 4 & 4 \\
$\mathbf{1 3}$ & 13 & 4 & 4 \\
$\mathbf{1 4}$ & 14 & 4 & 4 \\
$\mathbf{1 5}$ & 15 & $\mathbf{3}$ & $\mathbf{4}$ \\
$\mathbf{1 6}$ & 16 & 4 & 4 \\
$\mathbf{1 7}$ & 17 & 4 & 4 \\
$\mathbf{1 8}$ & 18 & 4 & 4 \\
$\mathbf{1 9}$ & 19 & 4 & 4 \\
$\mathbf{2 0}$ & 20 & 4 & 4 \\
$\mathbf{2 1}$ & 21 & 4 & 4 \\
$\mathbf{2 2}$ & 22 & 4 & 4 \\
$\mathbf{2 3}$ & 23 & 4 & 4 \\
$\mathbf{2 4}$ & 24 & 3 & 4 \\
\hline TOTAL & & 93 & 96 \\
\hline & & &
\end{tabular}

Hasil evaluasi oleh 10 siswa kelas X BKP SMK N 2 Surakarta dapat dijelaskan dengan tabel sebagai berikut :

Tabel 6 Data hasil evaluasi oleh siswa No. $\begin{gathered}\text { No. } \\ \text { Butir }\end{gathered}$ Total Skor $\begin{gathered}\text { Skor } \\ \text { Maksimal }\end{gathered}$

$\begin{array}{llll}\mathbf{1} & 1 & 34 & 40 \\ \mathbf{2} & 2 & 31 & 40 \\ \mathbf{3} & 3 & 32 & 40 \\ \mathbf{4} & 4 & 35 & 40\end{array}$




\begin{tabular}{cccc}
$\mathbf{5}$ & 5 & 33 & 40 \\
$\mathbf{6}$ & 6 & 36 & 40 \\
$\mathbf{7}$ & 7 & 34 & 40 \\
$\mathbf{8}$ & 8 & 36 & 40 \\
\hline No. & No. & Total Skor & $\begin{array}{c}\text { Skor } \\
\text { Maksimal }\end{array}$ \\
\hline $\mathbf{9}$ & 9 & 34 & 40 \\
$\mathbf{1 0}$ & 10 & 37 & 40 \\
$\mathbf{1 1}$ & 11 & 35 & 40 \\
$\mathbf{1 2}$ & 12 & 34 & 40 \\
$\mathbf{1 3}$ & 13 & 35 & 40 \\
$\mathbf{1 4}$ & 14 & 34 & 40 \\
$\mathbf{1 5}$ & 15 & 33 & 40 \\
$\mathbf{1 6}$ & 16 & 31 & 40 \\
$\mathbf{1 7}$ & 17 & 32 & 40 \\
$\mathbf{1 8}$ & 18 & 36 & 40 \\
$\mathbf{1 9}$ & 19 & 35 & 40 \\
$\mathbf{2 0}$ & 20 & 34 & 40 \\
$\mathbf{2 1}$ & 21 & 33 & 40 \\
$\mathbf{2 2}$ & 22 & 37 & 40 \\
$\mathbf{2 3}$ & 23 & 38 & 40 \\
$\mathbf{2 4}$ & 24 & 34 & 40 \\
\hline TOTAL & 823 & 960 \\
\hline & & & \\
\hline
\end{tabular}

\section{PEMBAHASAN}

\section{a. Proses Pengembangan Media Pembelajaran \\ Analisis gaya belajar}

dilakukan untuk mengetahui mayoritas gaya belajar siswa yang sedang menempuh mata pelajaran DasarDasar Konstruksi Bangunan dan Teknik Pengukuran Tanah tahun akademik 2018/2019 agar media pembelajaran yang akan dikembangakan sesuai dengan gaya belajar siswa. Analisis gaya belajar dilakukan dengan cara membagikan kuesioner yang berisi 10 pernyataan kepada siswa kelas X BKP dimana setiap pernyataan terdapat 4 poin jawaban dan siswa diperbolehkan untuk menjawab lebih dari 1 poin. Setiap poin jawaban mengandung unsur gaya belajar visual, auditory, read/write, dan kinesthetic.

Berdasarkan gambar 1 dapat dilihat bahwa mayoritas gaya belajar siswa BKP tahun akademik 2018/2019 adalah read ditunjukkan dengan prosentase sebesar 33,33\% yang merupakan prosentase tertinggi. Hasil analisis gaya belajar tersebut akan dijadikan dasar pengembangan media pembelajaran.

Berdasarkan hasil pengujian yang ditunjukkan pada tabel 2 diketahui bahwa fungsi dasar pada $e$ publication modul Dasar-Dasar Konstruksi Bangunan dan Teknik Pengukuran Tanah secara umum dapat berjalan sebagaimana fungsinya ditandai dengan tidak adanya kegagalan fungsi pada 12 poin pengujian yang dilakukan. Dimulai dari proses membuka aplikasi gitden reader hingga penggunaan menu yang tersedia pada aplikasi tersebut semua fungsi dapat digunakan. Ketiga jenis RAM smartphone yang digunakan untuk pengujian, semua fungsi dapat berjalan/digunakan. Tetapi pada smartphone dengan kapasitas RAM 512 MB respon dari perangkat terhadap perintah menu yg digunakan cukup lambat sehingga dirasa kurang nyaman saat digunakan dibandingkan dengan perangkat yang memiliki kapasitas 1024 MB dan 2048 MB.

Pengujian media pembelajaran oleh ahli dilakukan pada aspek materi dan aspek media. Instrumen pengujian menggunakan kuesioner yang dikeluarkan oleh BSNP (Badan Standar Nasional Pendidikan) yang dimodifikasi kemudian diberikan kepada ahli untuk memperoleh penilaian terhadap media pembelajaran e-publication yang telah dikembangkan.

Tabel 3 di atas menunjukkan skor pada setiap butir kuesioner. 
Jumlah butir kuesioner oleh ahli media adalah 23 butir, jika skor maksimal dari masing-masing butir kuesioner adalah 4, maka skor maksimal seluruh butir kuesioner ahli media adalah 92 poin. Hasil pengujian media pembelajaran oleh ahli media diatas diperoleh skor sebanyak 76 poin. Berdasarkan rumus PSA (Prosentase Setiap Aspek), yakni :

$$
P S A=\frac{\sum x}{\Sigma y} X 100 \%
$$

\section{Dimana :}

$\mathrm{x}=$ Alternatif jawaban terpilih setiap aspek

$\mathrm{y}=$ Alternatif jawaban ideal setiap aspek

Maka, Hasil Prosentase Validasi ahli media diperoleh sebesar $82,61 \%$. Berikut ini adalah analisis perhitungan validasi ahli media : Ahli media $=\frac{\sum x}{\sum y} X 100 \%$

Ahli media $=\frac{76}{92} \times 100 \%=$ $82,61 \%$

Dimana :

$\mathrm{x}=$ Jumlah skor terpilih ahli media

$\mathrm{y}=$ Jumlah skor maksimal

Gambar 2 di atas merupakan grafik hasil penilaian validasi ahli media dimana penilaian tersebut terdapat 2 indikator penilaian, yakni penilaian desain sampul modul dan penilaian isi modul. Indikator penilaian desain sampul meliputi poin nomor 1 sampai nomor 6 dengan hasil prosentase sebesar $91,67 \%$, sedangkan indikator penilaian desain isi meliputi poin nomor 7 sampai 23 dengan hasil prosentase sebesar $79,41 \%$.

Tabel 4 di atas menunjukkan skor pada setiap butir kuesioner. Jumlah butir kuesioner oleh ahli materi adalah 19 butir, jika skor maksimal dari masing-masing butir kuesioner adalah 4, maka skor maksimal seluruh butir kuesioner ahli materi adalah 76 poin. Hasil pengujian media pembelajaran oleh ahli materi diatas diperoleh skor sebanyak 59 poin.

Maka, Hasil Prosentase Validasi ahli materi diperoleh sebesar $77,63 \%$.

Berikut ini adalah analisis perhitungan validasi ahli materi :

Ahli materi $=\frac{\sum x}{\sum y} X 100 \%$

Ahli materi $=\frac{59}{76} \times 100 \%=$

$77,63 \%$

Dimana :

$\mathrm{x}=$ Jumlah skor terpilih ahli materi

$\mathrm{y}=$ Jumlah skor maksimal

Gambar 3 di atas merupakan hasil grafik penilaian validasi ahli materi dimana penilaian tersebut terdapat 4 indikator penilaian, yakni penilaian kesesuaian materi dengan SK dan KD, keakuratan materi, pendukung materi Pembelajaran, dan kemutakhiran materi. Indikator penilaian kesesuaian materi dengan SK dan KD meliputi poin nomor 1 sampai nomor 3 dengan hasil prosentase sebesar $83.33 \%$, indikator penilaian keakuratan materi meliputi poin nomor 4 sampai 10 dengan hasil prosentase sebesar 75\%, indicator penilaian pendukung materi pembelajaran meliputi poin nomor 11 sampai nomor 16 dengan hasil prosentase sebesar $87,50 \%$, serta indicator penilaian kemutakhiran materi meliputi poin nomor 17 sampai nomor 19 dengan hasil prosentase $58,33 \%$.

Berdasarkan hasil perhitungan di atas, hasil total validasi oleh ahli media diperoleh prosentase sebesar $82,61 \%$, dan total ahli materi diperoleh prosentase sebesar 77,63\%. Hasil keduanya diperoleh rata-rata prosentase sebesar 80,12\%.

Kriteria penilaian media pembelajaran pada Tabel 1 
menunjukkan bahwa persentase sebesar $80,12 \%$ termasuk dalam kategori sangat baik. Dengan demikian, media pembelajaran $e$ publication yang dikembangkan dinyatakan layak.

\section{b. Tingkat kelayakan Media Pembelajaran}

Tahap ini merupakan tahap evaluasi yang dilakukan oleh pendidik (guru) untuk memperoleh respon terhadap media pembelajaran yang telah dikembangkan. Tahap evaluasi dilakukan dengan membagikan kuesioner kepada guru pengampu mata pelajaran Dasar-Dasar Konstruksi Bangunan dan Teknik Pengukuran Tanah serta 10 siswa kelas X BKP (Bisnis Konstruksi dan Properti) SMKN 2 Surakarta.

Tabel 5 di atas menunjukkan skor pada setiap butir kuesioner. Jumlah butir kuesioner dari guru pengampu adalah 24 butir, jika skor maksimal dari masing-masing butir kuesioner adalah 4, maka skor maksimal seluruh butir kuesioner dari guru pengampu adalah 96 poin. Hasil respon dari guru pengampu diatas diperoleh skor sebanyak 93 poin.

Berikut ini adalah analisis perhitungan respon guru pengampu : Respon Guru $=\frac{\sum x}{\Sigma y} X 100 \%$

Respon Guru $=\frac{93}{96} \times 100 \%=$ 96,88\%

Dimana :

$\mathrm{x}=$ Jumlah skor terpilih Guru

$\mathrm{y}=$ Jumlah skor maksimal

Berdasarkan perhitungan di atas, respon guru pengampu diperoleh hasil $96,88 \%$. Kriteria penilaian media pembelajaran pada Tabel 1, menunjukkan bahwa prosentase sebesar 96,88\% termasuk dalam kategori sangat baik.
Tabel 6 di atas menunjukkan skor pada setiap butir kuesioner. Evaluasi siswa pada kelas X BKP SMK Negeri 2 Surakarta dilaksanakan dengan dibagikan kuesioner kepada 10 siswa sebagai sampel skala kecil. Jika jumlah butir kuesioner evaluasi siswa adalah 24 butir, skor maksimal 10 siswa dari masing-masing butir kuesioner adalah 40, maka skor maksimal seluruh butir kuesioner dari 10 siswa adalah 960 poin. Hasil respon dari 10 siswa diatas diperoleh skor sebanyak 823 poin.

Berikut ini adalah analisis perhitungan evaluasi siswa :

$$
\begin{gathered}
\text { Evaluasi Siswa }=\frac{\sum x}{\sum y} \times 100 \% \\
\text { Evaluasi Siswa }=\frac{823}{960} \times 100 \%
\end{gathered}
$$

$85,73 \%$

Dimana :

$\mathrm{x}=$ Jumlah skor terpilih ahli materi

$\mathrm{y}=$ Jumlah skor maksimal

Berdasarkan evaluasi oleh siswa diperoleh perhitungan prosentase sebesar $85,73 \%$. Kriteria penilaian media pembelajaran pada Tabel 3.6, menunjukkan bahwa prosentase sebesar $85,73 \%$ termasuk dalam kategori sangat baik.

Dengan demikian, respon guru dan respon siswa jika dijumlah dan di rata-rata diperoleh persentase sebesar 91,30\%.

Dengan hasil tersebut, maka media pembelajaran e-publication yang dikembangkan dinyatakan LAYAK untuk digunakan dalam pembelajaran. 


\section{SIMPULAN}

Berdasarkan hasil pengembangan media pembelajaran modul berbasis epublication, kesimpulan yang dapat diambil antara lain:

\section{a. Proses Pengembangan Pembelajaran}

1. Pengembangan

Media pembelajaran modul Dasar-Dasar Konstruksi Bangunan dan Teknik Pengukuran Tanah memiliki 6 tahap antara lain konsep, desain, pengumpulan material, penyusunan, pengujian, dan distribusi. Hasil analisis yang dilakukan pada tahap konsep menunjukkan bahwa mayoritas gaya belajar siswa adalah read/write ditandai dengan perolehan presentase $33,33 \%$. Hasil analisis materi diketahui bahwa materi untuk dimuat di dalam modul adalah materi kayu dan beton yang ada silabus DasarDasar Konstruksi Bangunan.

2. Media pembelajaran modul DasarDasar Konstruksi Bangunan dan Teknik Pengukuran Tanah berbasis e-publication dapat digunakan pada smartphone dengan kapasitas RAM 512 MB, 1024 MB dan 2048 MB ditandai dengan semua fungsi dasar $e$ publication dapat berjalan. Tetapi untuk kapasitas RAM 512 memiliki respon yang lebih lambat dibandingkan dengan kapasitas RAM yang lain.

3. Hasil pengujian terhadap media pembelajaran modul Dasar-Dasar Konstruksi Bangunan dan Teknik Pengukuran Tanah berbasis epublication oleh ahli memperoleh kategori SANGAT BAIK dengan persentase sebesar $80,12 \%$. Sehingga media pembelajaran yang telah dikembangkan dapat dinyatakan LAYAK.

\section{b. Tingkat kelayakan Media} Pembelajaran

Evaluasi terhadap media pembelajaran modul Dasar-Dasar Konstruksi Bangunan dan Teknik Pengukuran Tanah berbasis epublication berdasarkan respon dari guru pengampu mata pelajaran dan siswa memperoleh kategori SANGAT BAIK dengan persentase sebesar $91,30 \%$.

\section{SARAN}

Berdasarkan hasil pengembangan media pembelajaran Dasar-Dasar Konstruksi Bangunan dan Teknik Pengukuran Tanah, saran yang dapat diberikan antara lain:

1. Evaluasi terhadap media pembelajaran modul berbasis epublication pada penelitian ini hanya pada respon guru pengampu mata pelajaran dan siswa, peneliti selanjutnya diharapkan dapat melanjutkan hingga tahap pelaksanaan pembelajaran dengan siswa secara langsung.

2. Media pembelajaran modul DasarDasar Konstruksi Bangunan dan Teknik Pengukuran Tanah berbasis epublication ini selanjutnya diharapkan dapat di ujicobakan dalam pembelajaran untuk mengetahui keefektifan media yang telah dikembangkan.

3. Materi yang dimuat dalam modul berbasis e-publication ini masih terbatas pada dua kompetensi dasar sehingga dapat dikembangkan lagi dengan menambahkan materi pada kompetensi dasar yang lain.

4. Penggunaan modul Dasar-Dasar Konstruksi Bangunan dan Teknik Pengukuran Tanah berbasis e- 
publication sebaiknya menggunakan android smartphone dengan spesifikasi RAM (Random Acces Memory) diatas $1 \mathrm{~Gb}$ serta menggunakan aplikasi gitden reader agar semua teks, gambar, dan audio pada media dapat terbaca jelas.

\section{DAFTAR PUSTAKA}

Arikunto, S. 2006. Prosedur Penelitian Suatu Pendekatan Praktik, Jakarta : Rineka Cipta.

Arthana. I Ketut dan Dewi, Damajanti.2005. Evaluasi Media Pembelajaran. Surabaya: Teknologi Pendidikan - Unesa (Bahan Ajar Kuliah Teknologi Pendidikan)

Daryanto. (2013). Media Pembelajaran. Yogyakarta : Gava Media.

Fidler, Roger. (1997). Mediamorphosis: Understanding New Media. California: Pine Forge Press

Flemiing N.D. VARK : a guide to learnig style 2015, diakses pada 15 April 2018, dari www.vark-learn.com

Indriana, D. (2011). Ragam Alat Bantu Media Pengajaran. Jogjakarta: DIVA Press.

Southeast Asian Ministers of Educatioan Organization Regional Open Learning Centre (SEAMEO SEAMOLEC).2014. Buku Sumber: Buku Digital. 